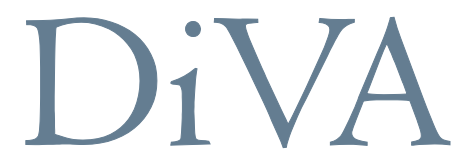

http://uu.diva-portal.org

This is an author produced version of a paper published in Solar Energy Materials and Solar Cells. This paper has been peer-reviewed but does not include the final publisher proof-corrections or journal pagination.

Citation for the published paper:

Green, S. et. al.

"Electrochromism in Nickel Oxide and Tungsten Oxide Thin Films: Ion Intercalation from Different Electrolytes"

Solar Energy Materials and Solar Cells, 2009, Vol. 93, Issue 12: 2050-2055 URL: http://dx.doi.org/10.1016/j.solmat.2009.05.009

Access to the published version may require subscription.

Published with permission from: Elsevier 


\title{
Electrochromism in nickel oxide and tungsten oxide thin films: Ion intercalation from different electrolytes
}

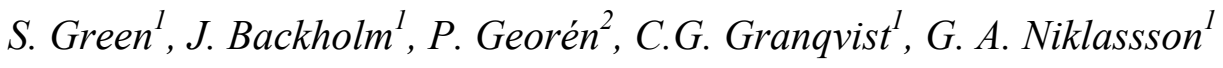 \\ ${ }^{1}$ Department of Engineering Sciences, The Angström Laboratory, Uppsala University, \\ P.O. Box 534, SE-751 21 Uppsala, Sweden \\ ${ }^{2}$ ChromoGenics Sweden AB, Märstagatan 4, SE-75323 Uppsala, Sweden
}

\begin{abstract}
Electrochromic $\mathrm{NiO}_{z}$ and $\mathrm{WO}_{y}$ thin films were prepared by sputtering and were used in a feasibility study aimed at investigating mixtures of these two oxides. The object was to identify a suitable electrolyte, compatible with both $\mathrm{NiO}_{z}$ and $\mathrm{WO}_{y}$. To that end we carried out cyclic voltammetry in potassium hydroxide $(\mathrm{KOH})$, propionic acid, and lithium perchlorate in propylene carbonate ( $\mathrm{Li}-\mathrm{PC}) . \mathrm{WO}_{y}$ could be coloured in propionic acid and $\mathrm{Li}-\mathrm{PC}$, while $\mathrm{NiO}_{z}$ could be coloured only in $\mathrm{KOH}$. Both films showed best stability in Li-PC, which hence is well suited for further studies of mixed $\mathrm{NiO}_{z}$ and $\mathrm{WO}_{y}$.
\end{abstract}

\section{Keywords}

Electrochromism, nickel oxide, tungsten oxide, cyclic voltammetry, spectrophotometry

\section{Introduction}

Nickel oxide $\left(\mathrm{NiO}_{z}\right)$ and tungsten oxide $\left(\mathrm{WO}_{y}\right)$ are well known electrochromic (EC) materials [1]. EC materials change their optical properties during electrochemical oxidation and reduction through ion insertion. There are two kinds of EC materials: cathodic (colouring upon ion insertion) and anodic (colouring upon ion extraction). $\mathrm{WO}_{y}$ is cathodic and turns blue when ions are inserted while $\mathrm{NiO}_{z}$ is anodic and turns brown when ions are extracted. The materials bleach if the processes are reversed. Different electroactive ions can be used; however small sized ions are preferred for the insertion chemistry. This work evaluated $\mathrm{H}^{+}$and $\mathrm{Li}^{+}$insertion cations.

Both $\mathrm{NiO}_{z}$ and $\mathrm{WO}_{y}$ are widely used for EC applications such as in smart windows [2]. A smart window consists of a number of layers: EC thin films (one anodic and one cathodic), electron conductive layers and an ion containing electrolyte. When a potential is applied over the smart window, ions in the electrolyte are transported between the EC layers and the transparency changes. In recent years materials development in this field has frequently been directed to the study of mixed oxides [3-6]. These promising materials may show improved optical, electrochemical and stability properties, as compared to the corresponding properties of the constituent oxides. From a fundamental point of view, mixing a cathodic material (such as $\mathrm{WO}_{y}$ ) and an anodic one (such as $\mathrm{NiO}_{z}$ ) is of considerable interest. Hence the objective of this work was to find a common electrolyte for thin films of $\mathrm{WO}_{y}$ and $\mathrm{NiO}_{z}$ to enable future studies of mixtures of the two oxides over the whole concentration range. Three electrolytes of different categories were investigated: protic and basic $1 \mathrm{M}$ potassium hydroxide $(\mathrm{KOH})$, protic and acidic $0.1 \mathrm{M}$ propionic acid, and aprotic and Lewis acidic $1 \mathrm{M}$ lithium perchlorate 
in propylene carbonate ( $\mathrm{Li}-\mathrm{PC})$. The choice of an appropriate electrolyte is complicated by the fact that $\mathrm{NiO}_{z}$ is sensitive to acids and that $\mathrm{WO}_{y}$ is sensitive to bases.

Furthermore, electrochemical cycling of $\mathrm{NiO}_{z}$ in Li-PC is rather poorly known and only a few studies have been published $[7,8]$.

Section 2 describes the experimental methods. The films were prepared by sputtering and were characterized by a number of techniques. The electrochemical properties were examined by cyclic voltammetry and the optical properties by spectrophotometry in the visible range. Section 3 presents results on the influence of the electrolytes on the electrochemical properties such as current density and charge capacity, and the optical properties such as transmittance and colouration efficiency. Structure, grain size, composition, and density are reported for the $\mathrm{NiO}_{z}$ and $\mathrm{WO}_{y}$ films. Results are also given for $\mathrm{WO}_{\mathrm{y}} /$ liquid electrolyte/ $\mathrm{NiO}_{\mathrm{z}}$ devices in order to verify the data on the individual thin films. Finally, section 4 presents the conclusions.

\section{Experimental methods}

Thin films of $\mathrm{NiO}_{z}$ and $\mathrm{WO}_{y}$ were prepared by reactive dc magnetron sputtering in a deposition system based on a Balzers UTT 400 unit. Depositions took place onto unheated glass plates, $5 \times 5 \mathrm{~cm}^{2}$ in size, precoated with transparent and electron conductive $\operatorname{In}_{2} \mathrm{O}_{3}: \mathrm{Sn}$ (ITO). Some films were made also on substrates of $\mathrm{C}$ and $\mathrm{Si}$. The films were deposited in an argon/oxygen atmosphere with an $\mathrm{O}_{2} / \mathrm{Ar}$ mass flow ratio of $2 \%$ for $\mathrm{NiO}_{z}$ and $13 \%$ for $\mathrm{WO}_{y}$. These ratios were chosen for optimal transparency of the as-deposited films. Previous work has shown that the EC properties are superior if the as-deposited films have maximum transparency [9-12]. The total pressure during thin film manufacturing was $\sim 30 \mathrm{mTorr}$, and the discharge power was 230 and $250 \mathrm{~W}$ when depositing $\mathrm{WO}_{y}$ and $\mathrm{NiO}_{z}$, respectively. The film thickness was $\sim 300 \mathrm{~nm}$ as measured by profilometry.

The structure and grain size of the films were determined by X-ray diffraction (XRD) using a Siemens D5000 diffractometer operating with $\mathrm{CuK}_{\alpha}$ radiation at a wavelength of $1.54 \AA$. The grain size $D$ was determined from Scherrers formula [13],

$$
D=\left(k \cdot \lambda_{x}\right) /(\beta \cdot \cos \theta)
$$

where $k$ is the shape factor, $\lambda_{x}$ is the $\mathrm{X}$-ray wavelength, $\beta$ is the full width at half maximum of the $\mathrm{X}$-ray diffraction peak, and $\theta$ is the diffraction angle.

Composition and density were determined by Rutherford backscattering spectroscopy (RBS) applied to films deposited onto $\mathrm{C}$ substrates. The measurements were carried out at the Uppsala Tandem Laboratory, using $2 \mathrm{MeV} 4 \mathrm{He}$ ions backscattered at an angle of $167^{\circ}$. The RBS data were fitted to a model of the film-substrate system by use of the program SIMNRA [14], from which the composition and the atomic concentration were found.

XPS used a PHI Quantum 2000 Scanning ESCA Microprobe operating with monochromated $\mathrm{Al} \mathrm{K} \alpha$ radiation and a pass energy of $46.95 \mathrm{eV}$. The XPS measurements were only performed at the surface of the sample, i.e. no presputtering was done. The presence of $\mathrm{W} 4 \mathrm{f}, \mathrm{Ni} 2 \mathrm{p}, \mathrm{O} 1 \mathrm{~s}$ and $\mathrm{C} 1$ was investigated and the atomic concentration was achieved by fitting a Gauss-Lorentz curve to the spectra. 
Electrochemical and optical properties were investigated for the various thin film materials and electrolytes. Cyclic voltammetry (CV) showed alterations of current density and charge capacity of the film in the chosen potential region. Optical measurements indicated changes in spectral transmittance modulation whitin the $380<$ $\lambda<800 \mathrm{~nm}$ wavelength range upon variations of the potential. These electrochemical and optical measurements were combined to determine the colouration efficiency (CE) between the coloured and the bleached state. $\mathrm{CE}$ is defined as the change in optical density $(O D)$ per unit of inserted charge $(Q)$, i.e.

$$
C E=\Delta(O D) / \Delta Q
$$

A high CE provides a large optical modulation for a small amount of charge, which is desirable for smart window applications. If the changes in reflectance between the bleached and coloured states are negligible, the CE can be obtained by

$$
C E=\left(\ln \left(T_{\text {Bleached }} / T_{\text {Coloured }}\right)\right) /(\Delta Q)
$$

where $T_{\text {Bleached }}$ and $T_{\text {Coloured }}$ denote transmittance in bleached and coloured states, respectively, and $\Delta Q$ is a mean value of the exchanged charge needed to achieve the optical modulation.

In the $\mathrm{CV}$ measurements the electrodes were oxidized and reduced in a three electrode electrochemical cell. The electrochemical instrumentation embodied a computer controlled ECO Chemie Autolab/GPES interface. A scan rate of $10 \mathrm{mV} / \mathrm{s}$ was utilized in all experiments. The films were electrochemically cycled in three different electrolytes: $1 \mathrm{M} \mathrm{KOH}, 0.1 \mathrm{M}$ propionic acid, and $1 \mathrm{M} \mathrm{Li}-\mathrm{PC}$. When using $\mathrm{KOH}$ and propionic acid the counter electrode was platinum and the reference electrode was $\mathrm{Ag} / \mathrm{AgCl}$. For the case of Li-PC, both counter and reference electrodes were Li foils. All potential values are given versus the standard hydrogen (SHE) potential. Li is reactive if exposed to air and moisture and hence all experiments with Li-PC were carried out inside an argon filled glove box. The number of inserted ions per $\mathrm{NiO}_{z}$ or $\mathrm{WO}_{y}$ unit, after stabilization, was calculated from

$$
x=(Q \cdot M) /\left(e \cdot A \cdot d \cdot \rho \cdot N_{A}\right) .
$$

Here $Q$ was taken as an average of inserted and extracted charge (if those were different). $M$ is molar mass, $e$ is elementary charge, $A$ is intercalated/deintercalated area, $d$ is film thickness, $N_{A}$ is Avogadro's constant, and $\rho$ is film density.

The optical measurements were carried out in situ during electrochemical cycling with a fibre optic spectrophotometer from Ocean optics. The entire electrochemical cell was put between a tungsten halogen lamp and a detector, as depicted in Fig. 1. When the film was cycled in $\mathrm{KOH}$ or propionic acid, the counter electrode was put opposite to the reference electrode. The transmittance was measured at $\lambda=500 \mathrm{~nm}$ for the whole cycle. One cycle means that the EC film goes from fully bleached to fully coloured and then back again. The transmittance was also recorded at fully coloured and bleached states for $380<\lambda<800 \mathrm{~nm}$. The optical measurements were always made after pre-cycling for about ten cycles to ensure the reversibility of oxidation/reduction. The $100 \%$ level 
was taken as the transmittance of the cell containing only the liquid electrolyte. A twoterminal measurement was performed in the experiments with $\mathrm{WO}_{y} /$ liquid electrolyte $/ \mathrm{NiO}_{z}$ devices. The $100 \%$ level was then set as the transmittance of the empty glass cell.

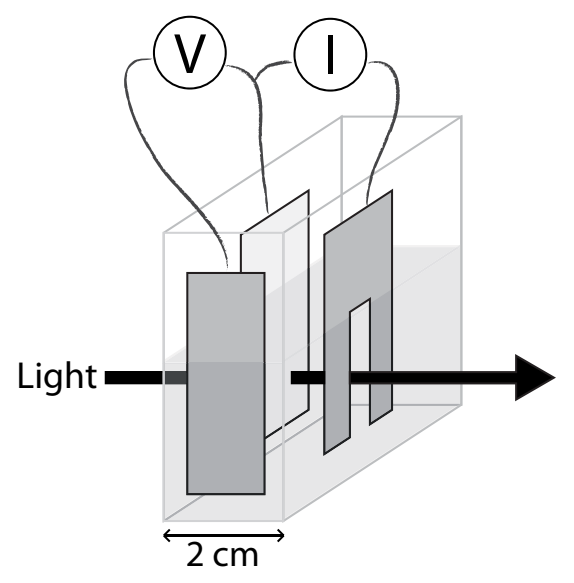

Figure 1: Schematic of the set-up for combined optical and electrochemical measurements. Current and voltage are denoted $I$ and $V$, respectively. The glass cell was filled with electrolyte and the electrodes positioned with a distance of $\sim 1.5 \mathrm{~cm}$ between the working and counter electrode. The whole electrochemical cell was put between a tungsten halogen lamp and a detector for optical measurements.

\section{Results}

\subsection{Tungsten Oxide}

The $\mathrm{WO}_{y}$ thin films were characterized by XRD, RBS and XPS. XRD showed no diffraction peaks, i.e. the $\mathrm{WO}_{y}$ films were amorphous. RBS yielded that the films were characterized by $\mathrm{y} \sim 3.1+/-0.1$ and the density was about $5.2 \mathrm{~g} / \mathrm{cm} 3$. XPS compositions were found to be uncertain because of organic residues on the surface.

In CV measurements on $\mathrm{WO}_{y}$, only $0.1 \mathrm{M}$ propionic acid and $1 \mathrm{M} \mathrm{Li}-\mathrm{PC}$ could be used since $1 \mathrm{M} \mathrm{KOH}$ etched away the film almost immediately. The first scan in the CVs started at the equilibrium potential and the electrochemical ranges were optimized regarding reversibility and chemical reactions. The potential ranges were -0.3 to 0.6 and -1.0 to $0.8 \mathrm{~V}$ vs SHE in propionic acid and Li-PC, respectively. Attempts to improve the charge capacity in propionic acid by increasing the negative potential limit resulted in irreversible reduction of the material. In propionic acid the films obtained a milky appearance after $\sim 30$ cycles. The charge capacities for $\mathrm{WO}_{y}$ were 26.0 and $5.2 \mathrm{mC} / \mathrm{cm}^{2}$ in $1 \mathrm{M} \mathrm{Li}-\mathrm{PC}$ and $0.1 \mathrm{M}$ propionic acid, respectively. The difference is probably due to the use of different potential ranges or ensued from the intercalation of $\mathrm{Li}^{+}$ions being easier. For the chosen potential ranges, the $x$-values were $0.07\left(\mathrm{H}^{+} / \mathrm{WO}_{y}\right)$ when using propionic acid and $0.36\left(\mathrm{Li}^{+} / \mathrm{WO}_{y}\right)$ when using $\mathrm{Li}-\mathrm{PC}$.

Fig. 2 (a) and (b) show changes of the transmittance at $\lambda=550 \mathrm{~nm}$ during intercalation of $\mathrm{H}^{+}$and $\mathrm{Li}^{+}$, respectively. The film was initially transparent and, as the potential was lowered, reduction occurred and the films were coloured. When the lower potential limit was reached, the potential scan was reversed and the film was oxidized, i.e., emptied of inserted ions, and bleached. The optical modulation was larger for films cycled in Li-PC 
than in propionic acid, as can be seen in Fig. 3. However, the colouration efficiency was almost the same for the film cycled in propionic acid and in Li-PC, at least for $380<\lambda<$ $800 \mathrm{~nm}$.
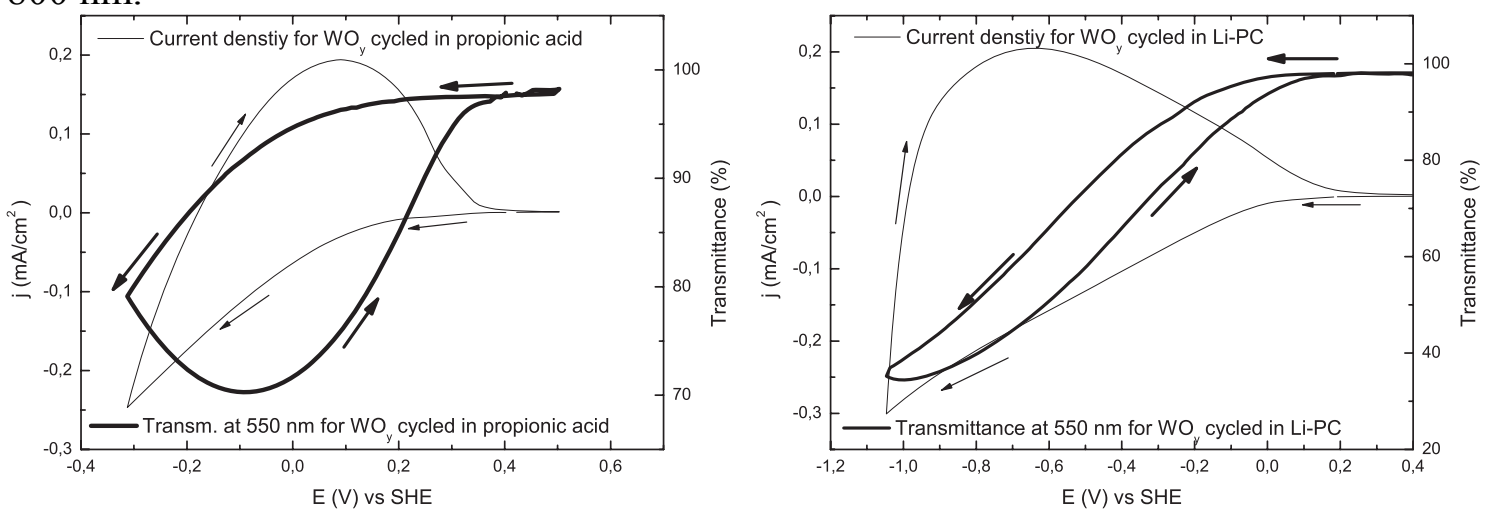

Figure 2: Current density and optical transmittance at $550 \mathrm{~nm}$ for $\mathrm{WO}_{\text {y }}$ measured in situ upon electrochemical cycling at $10 \mathrm{mV} / \mathrm{s}$ in (a) $0.1 \mathrm{M}$ propionic acid and (b) $1 \mathrm{M} \mathrm{Li}$-PC. The reference for the optical measurement is the glass cell containing the liquid electrolyte.

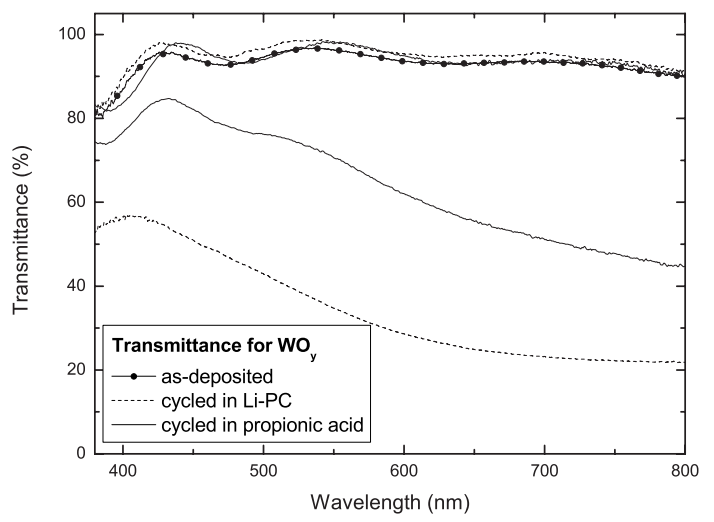

Figure 3: Spectral transmittance for $\mathrm{WO}_{y}$ cycled in $1 \mathrm{M} \mathrm{Li-PC}$ and $0.1 \mathrm{M}$ propionic acid. Data are shown for bleached and coloured states. The reference for the optical measurements is the glass cell containing the liquid electrolyte.

\subsection{Nickel Oxide}

Fig. 4 shows an XRD pattern for a NiO film. The peaks were assigned to the cubic phase of $\mathrm{NiO}$ [15]. The XRD spectrum indicated that the $\mathrm{NiO}_{z}$ film was polycrystalline and had a grain size of about $26.5 \mathrm{~nm}$, calculated by equation 1. RBS showed that $z$ was about 1.3 and the density $\rho$ about $3.9 \mathrm{~g} / \mathrm{cm}^{3}$. The composition was consistent with XPS measurements. By examining the carbonate contribution to $\mathrm{C} 1$ at $289 \mathrm{eV}$ by XPS it was concluded that about $10 \%$ of the oxygen was bound to carbon. The films are probably not pure $\mathrm{NiO}_{z}$, but also contain hydroxide phases, as shown by Avendano et al. [16]. 


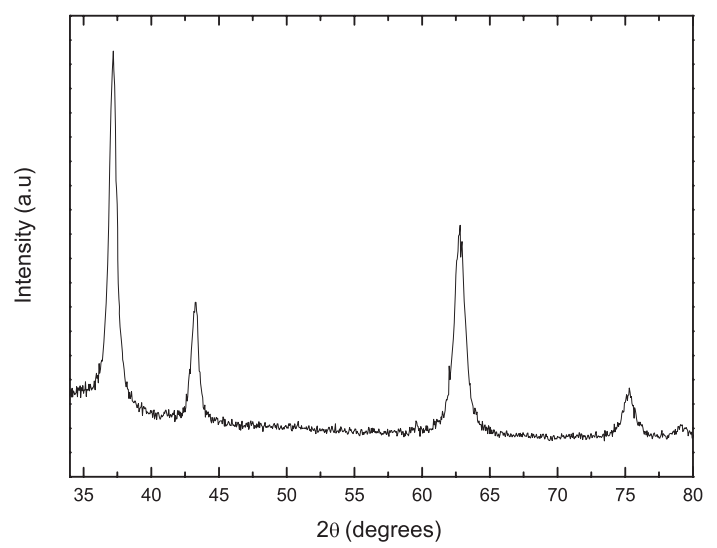

Figure 4: XRD spectrum for $\mathrm{NiO}_{z}$ deposited on $\mathrm{Si}$.

$\mathrm{NiO}_{z}$ was compatible with all three electrolytes. The first CV scan started at the equilibrium potential, and the electrochemical ranges were optimized regarding reversibility and chemical reactions. The potential ranges were -0.3 to $0.8,+0.2$ to 1 and -0.55 to $0.95 \mathrm{~V}$ vs SHE for cycling in $\mathrm{KOH}$, propionic acid, and Li-PC, respectively. At the positive potential limit in Li-PC, some reaction occurred which resulted in a dramatic decrease in the oxidation peak; it was possibly due to passivation or some other deteriorating electrochemical reactions. The oxidation peak was enhanced if the oxidation limit was increased, which supports the hypothesis of surface passivation, possibly due to electrolyte oxidation and the formation of a surface layer. For propionic acid, a difficulty ensues from the fact that $\mathrm{NiO}_{z}$ is sensitive to acids, and an increased positive potential limit resulted in enhanced irreversibility and even removal of the film.

Voltammograms for $\mathrm{NiO}_{z}$ cycled in different electrolytes are given in Fig. 5 (a) and (b). Large differences were observed among the voltammograms: specifically, the oxidation and reduction peaks increased in $\mathrm{KOH}$ during cycling, while the opposite was found in the two other electrolytes. The increasing peaks in $\mathrm{KOH}$ might be due to the formation of $\mathrm{NiO}_{z} \mathrm{H}_{w}$ on grain or pore surfaces [17]. The charge capacity for $\mathrm{NiO}_{z}$ was 14.5 $\mathrm{mC} / \mathrm{cm}^{2}$ in $\mathrm{KOH}, 1.2 \mathrm{mC} / \mathrm{cm}^{2}$ in Li-PC and $1.5 \mathrm{mC} / \mathrm{cm}^{2}$ in propionic acid. Evidently the charge capacity is much higher for films cycled in $\mathrm{KOH}$ than in $\mathrm{Li}-\mathrm{PC}$ and propionic acid. For the chosen potential ranges and after stabilization, the $x$-values were $\sim 0.1$ $\left(\mathrm{H}^{+} / \mathrm{NiO}_{z}\right), 0.01\left(\mathrm{H}^{+} / \mathrm{NiO}_{z}\right)$, and $0.008\left(\mathrm{Li}^{+} / \mathrm{NiO}_{z}\right)$ when using $\mathrm{KOH}$, propionic acid, and Li-PC, respectively.

The collected evidence is that another kind of electrochemistry is involved when $\mathrm{NiO}_{z}$ is exposed to $\mathrm{KOH}$ than to the two other electrolytes, i.e., the $\mathrm{pH}$-value seems to be important for the $\mathrm{NiO}_{z}$ reaction. The Pourbaix diagram for $\mathrm{Ni}$ verifies that this metal is stable at high $\mathrm{pH}$ and that corrosion occurs for low $\mathrm{pH}$ [18]. French et al [19] discovered that in $\mathrm{LiOH}$ the $\mathrm{H}^{+}$inside the film deintercalate to combine water together with $\mathrm{OH}^{-}$ and that it this reaction that causes the ion movements. This agrees with the work of Avendaño et al [17] that showed that protons were the ones responsible for the induced current density. So even if no free $\mathrm{H}^{+}$exists in the $\mathrm{KOH}$ electrolyte, protons are still the dependable ions. In propionic acid and Li-PC on the other hand it seems that no charge is getting extracted from the as-deposited film itself, i.e. $\mathrm{H}^{+}$and $\mathrm{Li}^{+}$inside the electrolyte are the ones causing the optical modulation. The applied potential is obviously not powerful enough to deintercalate ions from the films itself. In $\mathrm{KOH}$ on the other hand the $\mathrm{H}^{+}$seems to get a lot of help from the $\mathrm{OH}^{-}$. 

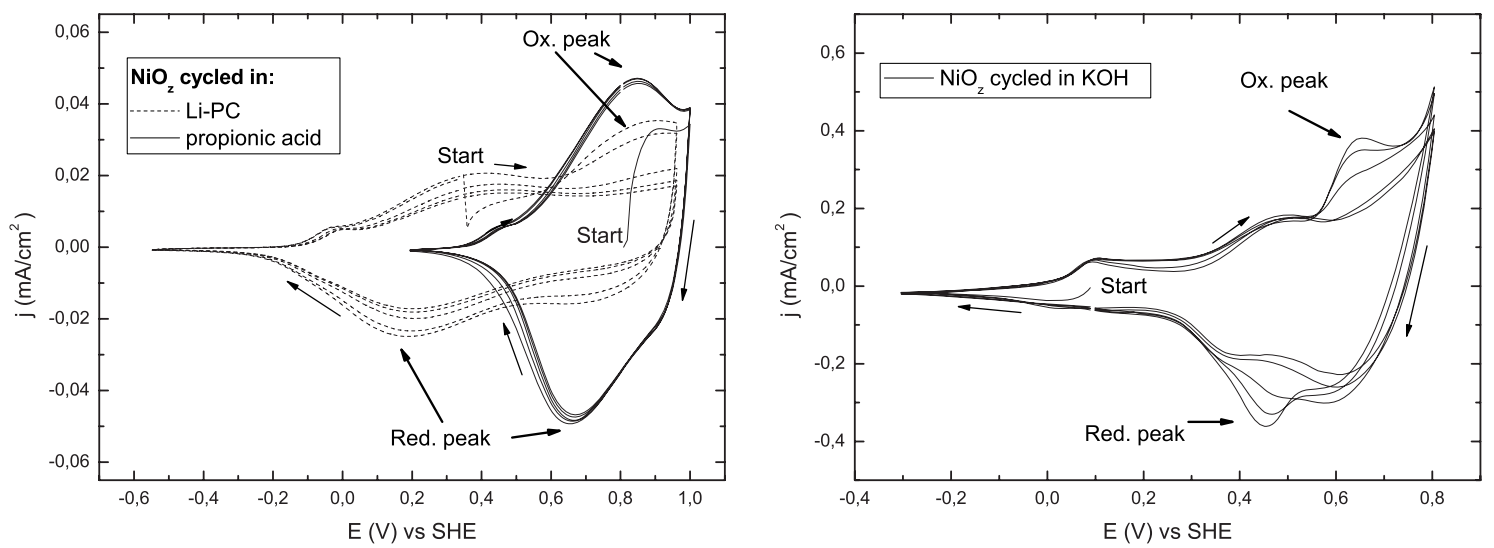

Figure 5: Cyclic voltammograms for $\mathrm{NiO}_{z}$ cycled in (a) $0.1 \mathrm{M}$ propionic acid and $1 \mathrm{M} \mathrm{Li}$-PC, and (b) $\mathrm{KOH}$. The scan rate was $10 \mathrm{mV} / \mathrm{s}$ and the five different sweeps correspond to cycle number $1,2,10$, 20 and 30.

Fig. 6 (a), (b) and (c) show the evolution of the transmittance at $\lambda=550 \mathrm{~nm}$ during electrochemical cycling. The initial transmittance of the $\mathrm{NiO}_{z}$ film was $\sim 85 \%$. Immersing the film in $\mathrm{KOH}$ and sweeping towards higher potentials led to oxidation, i.e., ions were extracted, and the film was coloured. When the positive potential limit was reached the potential scan was reversed and the film was reduced and bleached again. If the film was immersed in propionic acid or Li-PC the film was only bleached compared to the as-deposited state and hardly coloured at all, see Fig. 6.
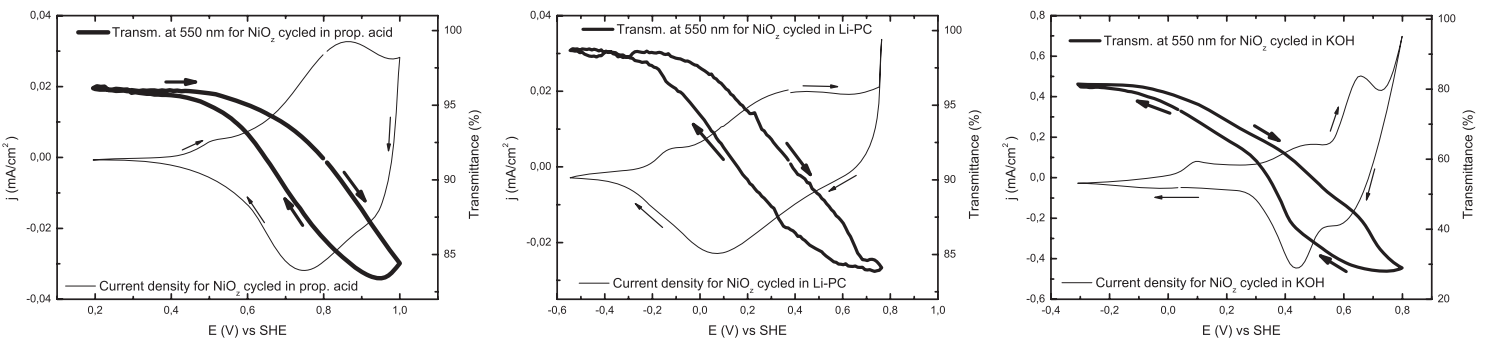

Figure 6: Current density and optical transmittance at $550 \mathrm{~nm}$ for $\mathrm{NiO}_{z}$ measured in situ upon electrochemical cycling at 10mV/s in (a) $0.1 \mathrm{M}$ propionic acid, (b) $1 \mathrm{M} \mathrm{Li-PC}$ and (c) $1 \mathrm{M}$ KOH. The reference for the optical measurement is the glass cell containing the liquid electrolyte.

Fig. 7 shows that the optical modulation was superior for $\mathrm{NiO}_{z}$ cycled in $\mathrm{KOH}$. For the applied potential ranges it was also observed that $\mathrm{KOH}$ only colours the film relative to the state of the as-deposited film, while Li-PC and propionic acid only bleach the film relative to the as deposited case. Even though the optical modulation was largest when using $\mathrm{KOH}$, the colouration efficiency was larger for Li-PC and propionic acid, which gives a hint that the optical modulation would be improved if one could increase the charge capacity of the film in the latter electrolytes. 


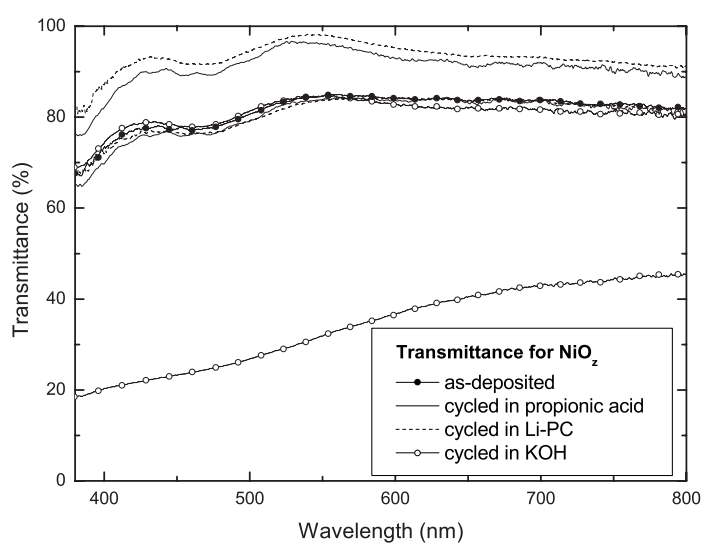

Figure 7: Spectral transmittance for $\mathrm{NiO}_{\mathrm{z}}$ cycled in $1 \mathrm{M} \mathrm{KOH,} 1 \mathrm{M} \mathrm{Li}-\mathrm{PC}$, and $0.1 \mathrm{M}$ propionic acid. Data are shown for the bleached and coloured states. The reference for the optical measurement is the glass cell containing the liquid electrolyte.

\section{3 $\mathrm{WO}_{\mathrm{y}} /$ liquid electrolyte $/ \mathrm{NiO}_{\mathrm{z}}$ devices}

The experiments reported above indicate that both Li-PC and propionic acid are usable electrolytes for $\mathrm{NiO}_{z}$ and $\mathrm{WO}_{y}$. As verification, those electrolytes were used in $\mathrm{WO}_{y} /$ liquid electrolyte $/ \mathrm{NiO}_{z}$ devices. The charge capacity was measured to be 1.5 to 2 $\mathrm{mC} / \mathrm{cm}^{2}$ for both electrolytes. The low charge capacity indicates that the $\mathrm{NiO}_{z}$ film limits the amount of available charge. The $x$-values for the two films in the $\mathrm{WO}_{y} /$ liquid electrolyte $/ \mathrm{NiO}_{z}$ device were $\sim 0.01\left(\mathrm{H}^{+} / \mathrm{NiO}_{z}\right.$ and $\left.\mathrm{Li}^{+} / \mathrm{NiO}_{z}\right)$ and $\sim 0.03\left(\mathrm{H}^{+} / \mathrm{WO}_{y}\right.$ and $\mathrm{Li}^{+} / \mathrm{WO}_{y}$ ) for propionic acid and $\mathrm{Li}-\mathrm{PC}$, respectively.

Fig. 8 shows transmittance modulation at $\lambda=550 \mathrm{~nm}$ during electrochemical cycling. The difference between the transmittance in the coloured and bleached states for these simple devices is comparable to values given in the literature for solid-state devices [2, $20]$. This is remarkable in view of the very low intercalation levels quoted above for the dark state of our model devices and suggests that there is room for considerable improvements of the optical contrast in state-of-the-art devices.
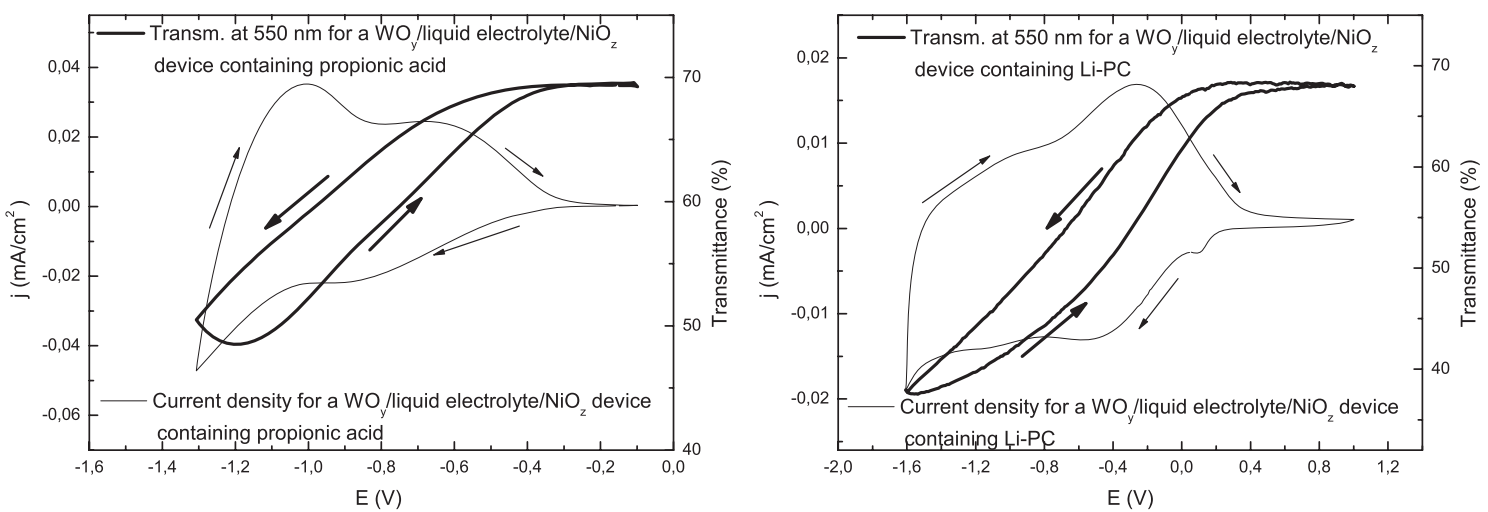

Figure 8: Current density and optical transmittance at $550 \mathrm{~nm}$ for a $\mathrm{WO}_{y} /$ liquid electrolyte/ $\mathrm{NiO}_{z}$ device cycled at $10 \mathrm{mV} / \mathrm{s}$ in (a) $0.1 \mathrm{M}$ propionic acid and (b) $1 \mathrm{M} \mathrm{Li-PC.}$

Fig. 9 shows that the optical modulation is larger for Li-PC than for propionic acid in the visible range. For that reason, and accounting for the fact that propionic acid resulted in more irreversibility and surface reactions, Li-PC was found to be the best suited electrolyte for devices made of $\mathrm{NiO}_{z}$ and $\mathrm{WO}_{y}$. 


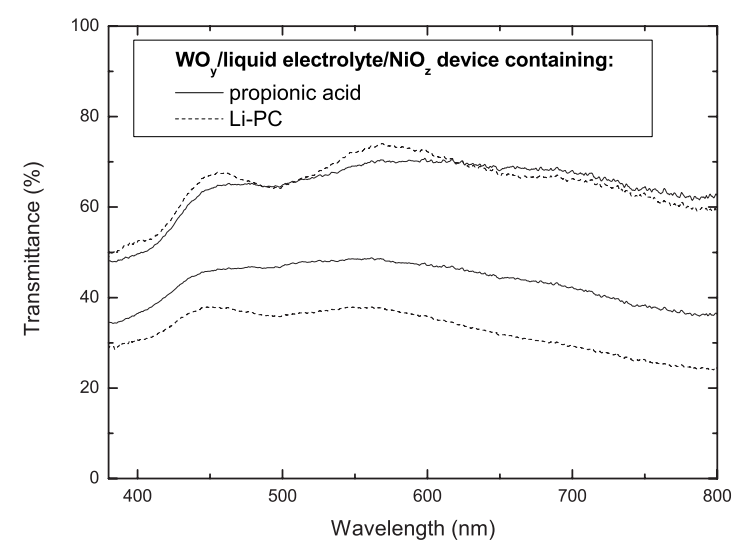

Figure 9: Spectral transmittance for a WO $\mathrm{W}_{y}$ /liquid electrolyte/ $\mathrm{NiO}_{z}$ device cycled in the indicated electrolytes. Data are shown for bleached and coloured states.

\section{Conclusions}

The two electrochromic materials $\mathrm{NiO}_{z}$ and $\mathrm{WO}_{y}$ were cycled in three different electrolytes, specifically being protic and basic $1 \mathrm{M}$ potassium hydroxide, protic and acid $0.1 \mathrm{M}$ propionic acid, and aprotic and Lewis acidic $1 \mathrm{M}$ lithium perchlorate in propylene carbonate. $\mathrm{WO}_{y}$ could be coloured in propionic acid and $\mathrm{Li}-\mathrm{PC}$ while $\mathrm{NiO}_{z}$ could be coloured only in $\mathrm{KOH}$. Propionic acid and Li-PC allowed cycling of $\mathrm{NiO}_{z}$ between an as-deposited and a very bleached state. The optical modulation of $\mathrm{NiO}_{z}$ was superior in $\mathrm{KOH}$. However the colouration efficiency for $\mathrm{NiO}_{z}$ in $\mathrm{KOH}$ was only half of that for the other two electrolytes. Use of Li-PC and propionic acid resulted in similar magnitudes of the colouration efficiency for the $\mathrm{NiO}_{z}$ and the $\mathrm{WO}_{y}$ films. A comparison between the two films shows that the colouration efficiency for $\mathrm{WO}_{y}$ is smaller at short wavelengths and rises up to the same value as that of $\mathrm{NiO}_{z}$ at longer wavelengths, see Fig. 10.

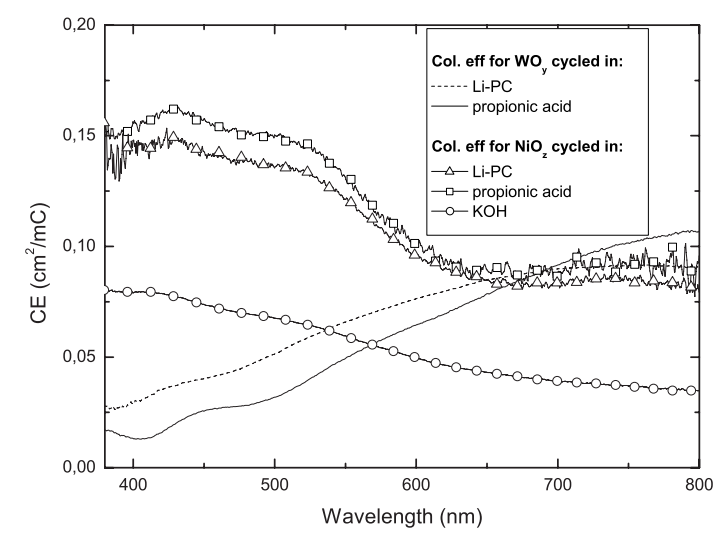

Figure 10: Spectral colouration efficiency for $\mathrm{WO}_{y}$ cycled in $1 \mathrm{M} \mathrm{Li-PC}$ and $0.1 \mathrm{M}$ propionic acid, and colouration efficiency for $\mathrm{NiO}_{z}$ cycled in $1 \mathrm{M} \mathrm{KOH,} 1 \mathrm{M} \mathrm{Li}-\mathrm{PC}$ and $0.1 \mathrm{M}$ propionic acid.

The conclusion for $\mathrm{NiO}_{z}$ is that the difference between immersing the film in propionic acid and in Li-PC is very small, and that $\mathrm{KOH}$ is superior when it comes to optical modulation and charge capacity. For $\mathrm{WO}_{y}, \mathrm{KOH}$ could not be used at all and $\mathrm{Li}-\mathrm{PC}$ was the electrolyte giving the best optical and electrochemical properties. Measurements on $\mathrm{WO}_{y} /$ liquid electrolyte $/ \mathrm{NiO}_{z}$ devices verified the previously mentioned results. Further considering the chemical problems related to propionic acid, such as irreversibility and 
surface reactions, Li-PC stands out as the best of the investigated electrolytes for further investigations on the electrochromism in mixed nickel tungsten oxide.

\section{Acknowledgments}

This work was supported by grants from the Swedish Research Council (VR) and from the Swedish Research Council for Environment, Agriculture Sciences and Spatial Planning (FORMAS). We are grateful to Jens Jensen and Leif Nyholm for valuable discussions

\section{References}

[1] C. G. Granqvist, Handbook of Inorganic Electrochromic Materials, Elsivier, Amsterdam 1995

[2] G. A. Niklasson, C. G. Granqvist, Electrochromism for smart windows: thin films of tungsten oxide and nickel oxide, and devices based on these, Journal of Materials Chemistry 17 (2007), 127156

[3] A. Azens, L. Kullman, Electrochromism in oxide films based on lanthanides, Solar Energy Materials \& Solar Cells 56 (1999) 193-203.

[4] E. Avendaño, L. Berggren, G. A. Niklasson, C. G. Granqvist, A. Azens, Electrochromic materials and devices: brief survey and new data on optical absorption in tungsten oxide and nickel oxide films, Thin Solid Films 496 (2006) 30-36

[5] E. Avendaño, A. Azens, G. A. Niklasson, C. G. Granqvist, sputter deposited electrochromic films and devices based on these: progress on nickel-oxide-based films, Materials Science and Engineering B 138 (2007) 112-117

[6] C. G. Granqvist, Transparent conductors as solar energy materials: a panoramic review, Solar Energy Materials \& Solar Cells 91 (2007) 1529-1598

[7] F. Decker, S. Passerini, R. Pileggi, B. Scrosati, The electrochromic process in non-stoichiometric nickel oxide thin film electrodes, Electrochimica Acta 37 (1992) 1033-1038

[8] S. Passerini, B. Scrosati, A. Gorenstein, The intercalation of lithium in nickel oxide and its electrochromic properties, Journal of the Electrochemical Society 137 (1990) 3297-3300 [9] L. Berggren, G. A. Niklasson, Influence of sputtering conditions on the solar and luminous optical properties of amorphous $\mathrm{Li}_{x} \mathrm{WO}_{y}$ thin films, Solar Energy Materials \& Solar Cells 85 (2005) 573-586

[10] L. Berggren, G. A. Niklasson, Optical absorption and durability of sputtered amorphous tungsten oxide films, Solid State Ionics 165 (2003) 51-58

[11] E. Avendaño, A. Azens, G. A. Niklasson, C. G Granqvist, Nickel-oxide-based electrochromic films with optimized optical properties, Journal of Solid State Electrochemistry 8 (2003) 37-39 [12] E. Avendaño, A. Azens, G. A. Niklasson, Properties of electrochromic nickel-vanadium oxide films sputter-deposited from non-magnetic alloy target, Proc. SPIE 4458 (2001) 154-163

[13] H. Klug, L. Alexander, X-ray Diffraction Procedures, John Wiley \& Sons, New York, 1954 [14] M.Mayer, SIMNRA, a simulation program for the analysis of NRA, RBS and ERDA, AIPConference Proceedings 475 (1999) 541.

[15] JCPDS-ICDD cardnumber:78-0423.

[16] E.Avendano, H.Rensmo, A.Azens, A.Sandell, G.deM.Azevedo, H.Siegbahn, G.A.Niklasson, C.G.Granqvist, Coloration mechanism in proton intercalated electrochromic hydrated NiOy and Ni1-xVxOy thin films, Journal of the Electrochemical Society, accepted May 2009.

[17] E. Avendaño, A. Azens, G. A. Niklasson, C. G Granqvist, Proton diffusion and electrochromism in hydrated $\mathrm{NiO}_{y}$ and $\mathrm{Ni}_{1-x} \mathrm{~V}_{x} \mathrm{O}_{y}$ thin films, Journal of the Electrochemical Society 152 (2005) F203-F212

[18] G. Wranglén, An Introduction to Corrosion and Protection of Metals, Butler \& Tanner, Frome and London, 1972

[19] H. M. French, M. J. Henderson, A. R. Hillman, E. Vieil, Ion and solvent transfer discrimination at a nickel hydroxide films exposed to $\mathrm{LiOH}$ by combined electrochemical quartz crystal microbalance (EQCM) and probe beam deflection (PBD) techniques, Journal of Electroanalytical Chemistry 500 (2001) 192-207

[20] A. Azens, G. Gustavsson, R. Karmhag, C. G. Granqvist, Electrochromic devices on polyester foil, Solid State Ionics 165 (2003) 1-5 